\title{
Actualización metodológica y material de los módulos de automatización en Ciclos Formativos de mantenimiento ante los retos de la industria 4.0
}

\author{
Boronat-Moll, Carles $^{\text {a }}$; Santolaria-Orrios, Emiliano ${ }^{\text {b }}$
}

${ }^{\mathrm{a} U n i v e r s i t a t ~ P o l i t e ̀ c n i c a ~ d e ~ V a l e ̀ n c i a+~ I E S ~ E d u a r d o ~ M e r e l l o, ~}{ }^{\mathrm{b}}$ IES Eduardo Merello

\begin{abstract}
Resumen
El objetivo principal de esta innovación educativa ha sido alejar al alumnado de paneles didácticos y simuladores para enfrentarse a sistemas automatizados con mayor similitud a los que encontrarán en su vida laboral y tener un pequeño contacto con los sistemas robotizados, para tal fin se han adecuado las prácticas de una asignatura de FP a la industria 4.0
\end{abstract}

Se han adquirido unos kits básicos del sistema MECLAB de FESTO para posteriormente ampliarlos. Éstos se han unido con los componentes existentes en el centro, sobre todo con los PLCS SIEMENS S7-1200 que fueron colocados en paneles con conexiones rápidas tipo banana, para montar sistemas automatizados que permitan a los alumnos mejorar su aprendizaje. También se ha adquirido un pequeño robot.

El sistema de trabajo ha sido realizar prácticas con las diferentes estaciones por separado y luego unirlas en un proyecto común.

Palabras clave: aprender haciendo, industria 4.0, robótica

\section{Introducción}

Los estudiantes del siglo XXI necesitan poder conectar los conocimientos y habilidades aprendidos académicamente y ser capaces de aplicarlos a nuevos escenarios desarrollando conocimiento tácito (Carneiro, 2007), así son las diversas competencias necesarias para los estudiantes son recogidas por Luna Scott (Scott, 2015) en su trabajo para la Unesco.

La Formación Profesional para poder facilitar una mayor integración laboral debe aproximarse a las tecnologías que las industrias adoptan, en este sentido la industria 4.0 es ya una realidad en ciernes (Liao et al. 2018), incluso en el cluster cerámico de Catellón (Hervas-Oliver et al., 2019), en área de influencia del instituto. 
La industria 4.0 comprende entre otras tecnologías de simulación y robótica (Culot et al., 2020) que son las dos tecnologías que mayormente se han trabajado en esta innovación educative.

\section{Objetivo}

Adaptar las prácticas de los alumnos en la asignatura Montaje y Mantenimiento de Líneas Automatizadas (176 h) de segundo del Grado Medio en Mantenimiento electromecánico (Orden 16/2015 y RD 1589/2011) que se imparte en el IES Eduardo Merello (Sagunt), para realizar simulaciones de ejercicios y además integrar un robot.

Estas prácticas se relacionan mayormente con las siguientes competencias profesionales del ciclo (RD 1589/2011):

e) Montar los sistemas mecánicos, hidráulicos, neumáticos y demás elementos auxiliares asociados a las instalaciones electromecánicas.

f) Montar sistemas eléctricos y de regulación y control asociados a las instalaciones electromecánicas, en condiciones de calidad y seguridad.

h) Realizar las pruebas y verificaciones, tanto funcionales como reglamentarias, de las instalaciones para comprobar y ajustar su funcionamiento.

i) Diagnosticar las disfunciones de los equipos y elementos de las instalaciones, utilizando los medios apropiados y aplicando procedimientos establecidos con la seguridad

k) Poner en marcha la instalación, realizando las pruebas de seguridad y de funcionamiento de las máquinas, automatismos y dispositivos de seguridad, tras el montaje o mantenimiento de una instalación. 1) Cumplimentar la documentación técnica y administrativa asociada a los procesos de montaje y de mantenimiento de las instalaciones.

m) Adaptarse a las nuevas situaciones laborales originadas por cambios tecnológicos y organizativos en los procesos productivos, actualizando sus conocimientos, utilizando los recursos existentes para el aprendizaje a lo largo de la vida y las tecnologías de la información y la comunicación.

\section{Desarrollo de la innovación}

La innovación se desarrolló durante los cursos 2018-19 y 2019-20. En el primer curso se procedió a comprar el sistema MECLAB de FESTO, consistente en una estación de 
fabricación flexible con cinta transportadora, agarre de pieza por ventosa y brazos actuados neumáticamente de posición NC o NO según el cableado de las electroválvulas, aunque la maqueta se completó con elementos industriales como sensores capacitivos, reed y otros, la mayoría de las entradas y la totalidad de las salidas tenían un tipo de conexión rápida que facilitaba el montaje y minimizaba los errores de cableado.

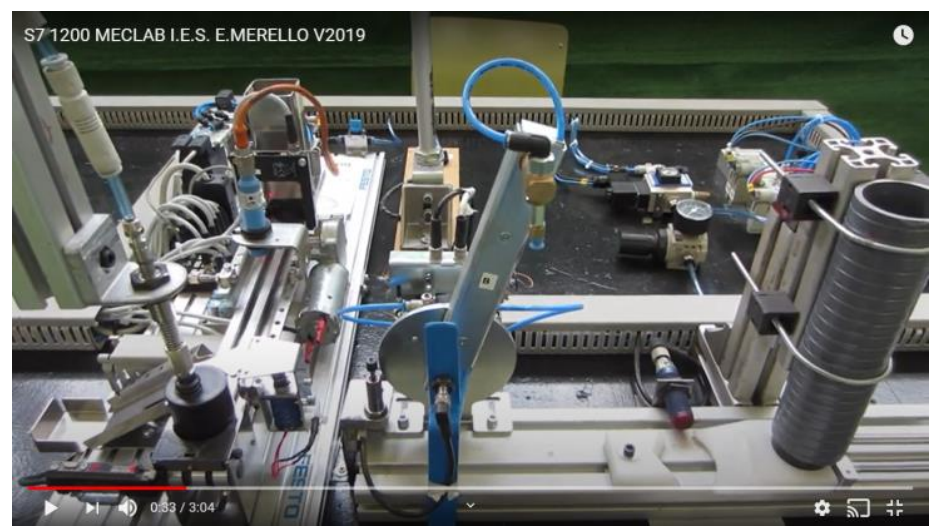

Imagen. 1 estación de fabricación flexible Meclab de Festo.

Fuente: Proyecto 2018-19. Estaciones

También el primer año se compró el Robot Dobot Magician, su software de programación es el DOBOTSTUDIO. El robot dispone de varios modos y lenguajes de programación. En nuestro caso se utilizó el sistema "TEACHING \& PLAYBACK". El robot tiene tres ejes de coordenadas tal y como puede apreciarse en la siguiente figura:

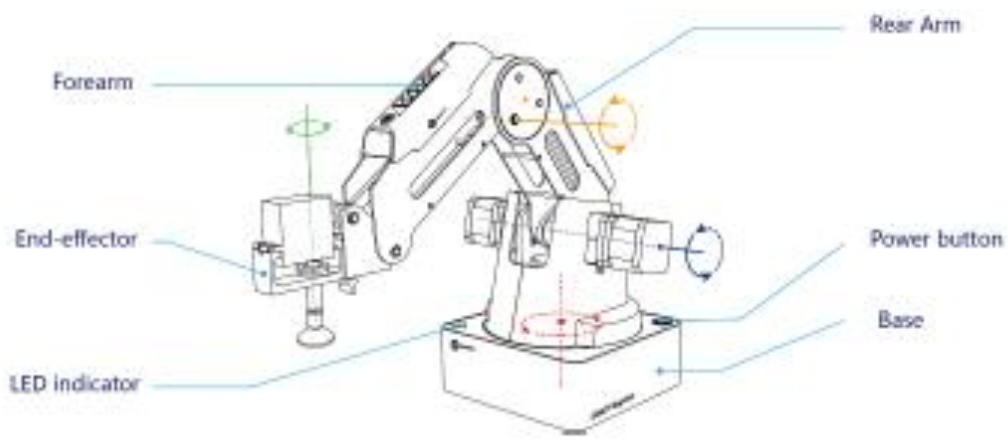

Fig 1. Ejes de coordenadas del Robot. Fuente: Dobot Magician User Guide.

$\mathrm{Y}$ en la siguiente figura podemos ver su área de trabajo y algunas de sus dimensiones. Las reducidas dimensiones del robot hacen que sea más fácil interactuar con la maqueta que también es de un tamaño bastante reducido. 
Actualización metodológica y material de los módulos de automatización en Ciclos Formativos de mantenimiento ante los retos de la industria 4.0

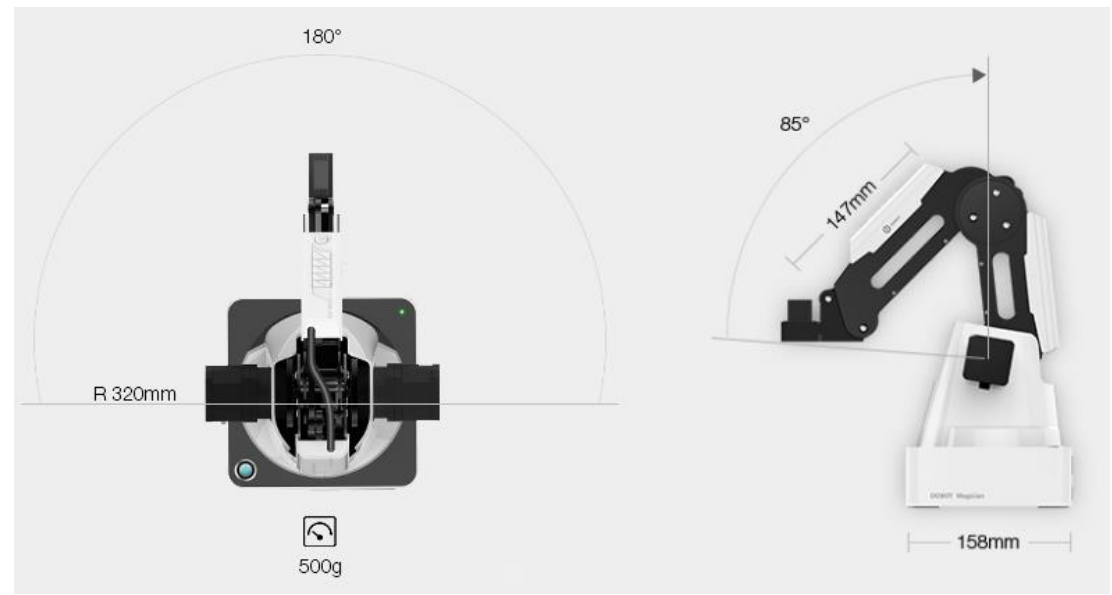

Fig 2. Area de trabajo del robot. Fuente: Dobot Magician Specifications

En el curso 2018-19 se diseñaron diversos ejercicios con el Meclab y con el robot por separado. Para automatizar la maqueta Meclab se utilizó el autómata S7-1200 y el software TIA-Portal de siemens, el lenguaje de programación utilizado fue el KOP (o por contactos).

En el segundo curso (2019-20) se procedió a acoplar la maqueta Meclab con el robot, en la siguiente imagen se puede ver un ejemplo:

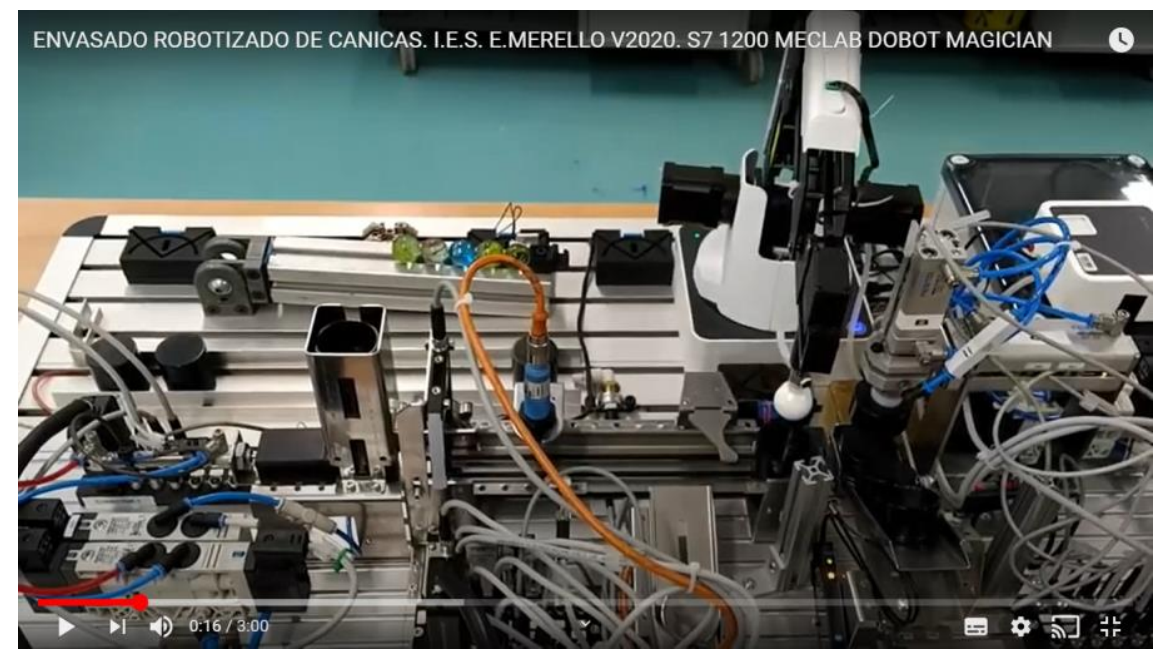

Imagen 2: Proyecto final curso 19-20. Integración de estaciones y robot. 


\section{Resultados}

Los resultados fueron una serie de prácticas, por ejemplo, estas son algunas de las actividades que los alumnos tenían que desarrollar con el robot:

Actividad del robot con un rotulador.

1. Calcula la cota $Z$ del "suelo".

2. Dibuja un cuadrado de $40 \mathrm{~mm}$ de lado a una altura de $30 \mathrm{~mm}$.

3. Dibuja un rectángulo en el papel de 40 x $80 \mathrm{~mm}$ con sus diagonales. Utiliza en todos los desplazamientos el operador MOVL.

4. Dibuja un rectángulo en el papel de 40 x $80 \mathrm{~mm}$ con sus diagonales. Utiliza en todos los desplazamientos el operador MOVJ y compáralo con el anterior.

5. Dibuja el objeto representado en el plano $n^{\circ} 1$.

Anteriormente a los ejercicios se dieron las iban aumentando en dificultad, además de una secuencia con el rotulador se propuso manejar la ventosa y una pinza.

Ejemplo de actividades con la estación Cargador de Meclab:

1. El equipo ha de poner una tapa y cerrar el bote. Configuración inicial con un solo detector de posición.

2. El equipo ha de poner una tapa y cerrar el bote dando tres golpes. Configuración inicial con un solo detector de posición.

3. El equipo ha de poner una tapa y cerrar el bote. Configuración 2, con cuatro detectores de posición.

4. El equipo ha de poner una tapa y cerrar el bote dando tres golpes. Configuración 2 con cuatro detectores de posición.

5. Añadir al ejercicio 3 una forma de detectar que no hay tapa. En ese caso ha de subir y el equipo ha de volver a posición inicial y activar un piloto luminoso hasta que confirmemos con un pulsador que hemos cargado el almacén vertical y podamos volver a empezar.

6. El equipo ha de poner una tapa y cerrar el bote. Configuración 3, con cuatro detectores de posición y un presostato. El cierre del bote se detectará por presión.

7. Añadir al ejercicio 3 un terminal HMI con dos imágenes. En la primera aparecerán los controles y en la segunda el estado de las entradas y salidas.

8. Añadir al ejercicio 5 un terminal HMI con tres imágenes. En la primera aparecerán los controles y la alarma de almacén vacío, en la segunda el estado de las entradas y salidas y en la tercera el número de botes cerrados.

9. Añadir modos de funcionamiento al ejercicio 7. Mantenimiento, Producción y Reposicionamiento. 
También se diseñaron actividades para la estación pinza y para la estación manipulador.

Finalmente se diseñaron una serie de actividades que unían el robot con la maqueta Meclab, un ejemplo es el que se puede ver en el vídeo, una cinta lleva la base de una caja hasta un determinado punto, el robot coge una canica y la deposita en la caja, un cilindro acoplado a un cilindro lineal coge la tapa y tapa la caja. Posteriormente el robot retira la caja tapada dejándola en un determinado punto.

\section{Conclusiones}

Los alumnos pudieron experimentar, poner en práctica y desarrollar lo aprendido en un enfoque pedagógico basado en aprender haciendo, muy relacionado con el aprendizaje procedimental (Rivas-Navarro, 2008), el aprendizaje se vuelve más significativo en la medida en que más sentidos son involucrados, la puesta en práctica de conocimientos además de ser motivadora para el alumno, hace que las teorías explicadas se asienten mejor en su cabeza y el aprendizaje sea más significativo (Romero-Ariza, M., \& QuesadaArmenteros, A. (2014).

Además, la maqueta Meclab junto con la integración del robot y la programación del autómata S7-1200 dan lugar a un trabajo complejo cercano a la realidad y a la industria 4.0, aunque con las evidentes limitaciones.

\section{Agradecimientos}

Agradecer a los alumnos su implicación en el desarrollo de las actividades y el cuidado de los equipos. También a la Generalitat Valenciana que ha concedido una ayuda de 3031,8 euros a este proyecto de investigación e innovación educativa (número de expediente 939142, convocatoria: RESOLUCIÓN de 11 de mayo de 2018, del director general de Política Educativa, por la que se convocan subvenciones y asignaciones económicas para desarrollar proyectos de investigación e innovación educativa en centros educativos sostenidos con fondos públicos de la Comunitat Valenciana, durante el curso académico 2018-2019).

Por último, agradecer también a la empresa Arcelor la concesión de una ayuda económica. 


\section{Referencias}

Carneiro, R. (2007). The big picture: understanding learning and meta-learning challenges. European Journal of Education, 42(2), 151-172.

Culot, G., Nassimbeni, G., Orzes, G., \& Sartor, M. (2020). Behind the definition of industry 4.0: Analysis and open questions. International Journal of Production Economics, 107617.

Dobot Magician User Guide v 1.7.0. Shenzhen Yuejiang Technology Co., Ltd $\underline{\text { https://www.dobot.cc/downloadcenter.html }}$

Dobot Magician Specifications. Shenzhen Yuejiang Technology Co., Ltd https://www.dobot.cc/dobot-magician/specification.html

España, Real Decreto 1589/2011, de 4 de noviembre, de 2011 por el que se establece el Título de Técnico en Mantenimiento Electromecánico y se fijan sus enseñanzas mínimas. BOE, 15 de diciembre de 2011, núm. 301, p. 137002- 137062.

España. Comunidad Valenciana. Orden 16/2015, de 5 de marzo de 2015, de la Consellería de Educación, Cultura y Deporte, por la que se establece para la Comunitat Valenciana el currículo del ciclo formativo de grado medio correspondiente al título de Técnico en Mantenimiento Electromecánico. DOGV, 25 de marzo de 2015, núm. 7482, p.6858-6884.

Hervas-Oliver, J. L., Estelles-Miguel, S., Mallol-Gasch, G., \& Boix-Palomero, J. (2019). A placebased policy for promoting Industry 4.0: the case of the Castellon ceramic tile district. European Planning Studies, 27(9), 1838-1856.

Liao, Y., Loures, E. R., Deschamps, F., Brezinski, G., \& Venâncio, A. (2018). The impact of the fourth industrial revolution: a cross-country/region comparison. Production, 28.

Proyecto final curso 18-19. Estaciones. https://www.youtube.com/watch?v=1pSTcLia7bA [Consulta: 13 de junio de 2020]. Nombre del vídeo: S7 1200 MECLAB I.E.S. E.MERELLO V2019

Proyecto final curso 18-19. Robot. https://www.youtube.com/watch?v=1MdQlxtvHi8 [Consulta: 13 de junio de 2020] Nombre del vídeo: INICIACIÓN A LA ROBÓTICA CON DOBOT MAGICIAN I.E.S. E.MERELLO V2019

Proyecto final curso 19-20. Integración de estaciones y robot. https://www.youtube.com/watch?v=HWCXFoRnRms [Consulta: 13 de junio de 2020] Nombre del vídeo: ENVASADO ROBOTIZADO DE CANICAS. I.E.S. E.MERELLO V2020. S7 1200 MECLAB DOBOT MAGICIAN

Rivas-Navarro, M. (2008). Procesos cognitivos y aprendizaje significativo. Comunidad de Madrid. Consejería de Educación. Viceconsejería de Organización Educativa.

Romero-Ariza, M., \& Quesada-Armenteros, A. (2014). Nuevas tecnologías y aprendizaje significativo de las ciencias. Enseñanza de las Ciencias, 32(1), 101-115.

Scott, C.L. (2015). The Futures of Learning 2: What Kind of Learning for the 21st Century? Education Research and Foresigh 14, November 2015. United Nations. Educational, Scientific and Cultural Organization working papers. 